\title{
THE EFFECT OF MAP-BASED MATERIALS AND ACTIVITIES ON GLOBAL DATA PRIVACY AWARENESS IN AN INFORMATION SYSTEMS COURSE
}

\author{
William A. Kapakos, Western Carolina University,wakapakos@email.wcu.edu \\ Barbara Jo White, Western Carolina University,whiteb@email.wcu.edu \\ Lorrie Willey, Western Carolina University, lwilley@email.wcu.edu \\ Janet C. Ford, Western Carolina University,jford@email.wcu.edu
}

\begin{abstract}
The proliferation of data breaches in recent years presents challenges for the information systems discipline. Public outcry over those breaches, at home and abroad, has drawn attention to the weakness of data privacy laws of the United States when compared to the laws of other nations. The Association to Advance Collegiate Schools of Business stresses the importance of providing business students a world view. Additionally, curriculum guidelines created by information systems organizations place an increasing emphasis on globalization as a topic or learning objective. Students in information systems programs will benefit from an awareness of data privacy laws and resulting legal obligations, and it is thus imperative that educators in this field develop and deliver effective educational experiences that will meet this need. This paper presents a study in which both passive and active mapbased learning experiences were presented in introductory information systems courses at the undergraduate level. The map-based learning experiences will be described, along with a discussion and analysis of the results of a survey administered at the end of the semester to measure student awareness of globalization.
\end{abstract}

Keywords: IS Globalization, IS Laws, Data Privacy, Active Learning

\section{INTRODUCTION}

For two days in April 2018, Mark Zuckerberg, CEO of Facebook, Inc., sat before a panel of congressional representatives and senators to answer pointed questions about the security of the personal information of millions of Facebook users. His testimony came in the midst of growing outrage over the Cambridge Analytica scandal, in which a Russian-American researcher affiliated with Cambridge University accessed the personal data of approximately 87 million Facebook users and their friends. The data was then shared with Cambridge Analytica, a subsidiary of a British firm with American ties that allegedly used the data to deliver content to American users in a bid to influence the 2016 presidential election (Meredith, 2018). This incident highlights the global interest in and application of personal data to impact not only commercial interests but also political interests. The scandal also drew renewed attention to the fact that data privacy laws in the United States (U.S.) are much less stringent than data privacy laws in other countries. While many American companies are at the forefront of collecting, analyzing, and utilizing personal data, they face increasing restrictions on such practices when they expand operations beyond U.S. borders. Consequently, awareness of data privacy and security and how it differs across political and geographical boundaries has become vital for students who will work in information systems (IS).

To provide IS students with awareness of global data privacy and security issues, educators in these disciplines must design, deliver, and evaluate learning opportunities that stress not only the technical aspects of IS but also the economic, cultural, ecological, and political aspects of IS in a global context. For example, data privacy and security laws differ across political and geographical boundaries which are visually depicted on world maps. Student learning using map-based activities, may be characterized as either passive or active. While both passive and learning activities have value, it is worthwhile to evaluate the efficacy of varied approaches to learning specific topics or concepts, such as global awareness.

This paper presents a study that compares the impact on student global awareness of both passive map materials and active map-based learning experiences. Discussion begins with an overview of the increased emphasis placed on global learning objectives by business and industry organizations, as well as a brief overview of the different dimensions of globalization and how data privacy and security have been impacted by increasing globalization of IS. 
The study, including its methodology and results, will then be presented, along with a proposal for continued exploration of map-based learning activities as a means to increase global awareness.

\section{LITERATURE REVIEW}

\section{Globalization in US Business College Education}

The Association to Advance Collegiate Schools of Business (AACSB), an accreditation body for business schools, recognizes that accreditation standards are mission based and encourage continuous improvement which yields a variety of quality programs (Romero, 2008). Within that framework, the AACSB stresses the importance of providing business students a world view. The AACSB has identified six categories that distinguish business operations worldwide: "cultural, legal/regulatory, political, economic, and financial and ... other" (Bruner, 2011, p. 238). In a 2011 report, the AACSB defined globalization as a "process" of "extending the reach of educational engagement beyond one's home borders and deepening the richness of understanding about the increasingly global foundation of business" (AACSB, 2011, p. 7).

Not only is globalization important for accreditation standards in colleges of business, but globalization is also recognized in various curriculum guidelines for undergraduate degree programs in IS and information technology (IT). For example, curriculum guidelines created by a long-standing partnership between the Association for Computing Machinery (ACM) and the Association for Information Systems (AIS) began with an initial collaboration in 1997 (Davis, Gorgone, Couger, Feinstein \& Longenecker, 1997), followed by an update emphasizing e-commerce five years later (Gorgone, Davis, Valacich, Topi, Feinstein \& Longenecker, 2003). The most recent update emphasized how information systems are used throughout global organizations (Topi, Valacich, Wright, Kaiser, Nunamaker Jr., Sipior \& Vreede, 2010). The guidelines place an emphasis on globalization with the terms global and globalization appearing more frequently from 1997 to 2010 and appearing as a topic or learning objective in an increasing number of core and elective classes over time (White, Hale \& Willey, 2014). With globalization listed as a learning objective within the IS curriculum, importance is placed on understanding how information systems have affected the evolution of globalization (Topi et al., 2010). This is not surprising since researchers in the area of globalization (Steger, 2009) have identified technology as one of the hallmarks of contemporary globalization. In addition to curriculum guidelines for IS programs, which place importance on globalization for college students, similar guidelines for undergraduate programs in IT also emphasize globalization. Furthermore, the Computing Curricula Guidelines for Undergraduate Degree Programs in Information Technology project, IT2017, presents suggested guidelines for IT programs and incorporates globalization into its curricular framework (Sabin, Alrumaih, Impagliazzo, Lunt, Zhang, Byers, Newhouse, Paterson, Peltsverger, Tang, Veer \& Viola, 2017).

\section{Globalization Dimensions}

Although the term globalization has generally been used inconsistently with vague interpretation, in both popular and academic literature it describes "a process, a condition, a system, a force, and an age" (Steger, 2009, p. 8). The conceptualization of globalization is an inherently dynamic process. State borders are often inundated with electronic and other flows of goods and services that sovereign nations can no longer effectively handle. Further, Steger believes that "political globalization is most visible in the rise of supraterritorial institutions and associations held together by common norms and interests" $(2009$, p. 66). This presents a challenge for students to understand how supraterritorial growth is altering the activities and the role of independent states. Emphasis regarding global awareness and attitudes (Pew Research Center, 2003) has been placed on educators to prepare $21^{\text {st-century students }}$ in a global society to become effective citizens (McPherson, Wang, Hsu, Tsuei \& Wood, 2007). Steger (2009) proposes that globalization is multidimensional with economic, cultural, ecological and political dimensions. At its core, globalization corresponds to change and signifies transformation as these four dimensions continually create new networks and activities that expand across political and geographical boundaries.

\section{Data Privacy as an Element of the Political Dimension of Globalization}

Data privacy concerns over the proliferation of data breaches have continued to fuel political interrelations across the globe. Political globalization is most relevant to this development as suprastate agencies, such as the EU, are beginning to emerge. In fact, beginning in 1990 a paradigm shift occurred when many world leaders agreed that cross-border wrongful acts no longer concerned only those affected (Steger, 2009). In addition, Baylis and Smith 
(2001) stress that well over a hundred regional governance agreements have been arranged dating back to 1945, with 20,000 regulatory measures issued from the EU.

The seemingly unending cases of data breaches have posed an enormous threat. For example, the 2017 Equifax data breach exposed sensitive personal data of over 143 million people, including individuals who are not U.S. citizens. In addition, Uber concealed its data breach, which affected 57 million customers and drivers, and attempted to pay hackers $\$ 100,000$ to delete the data (Lee, 2017). Furthermore, Alteryx Inc. exposed the personal information of 123 million American households when accidentally making a file public that contained addresses, phone numbers, ages, and other sensitive data (Lien, 2017).

As a result, public outcry has propelled U.S. data privacy laws to the forefront of cybersecurity efforts on a global scale. Lagging behind their global counterparts, including the EU, comprehensive national laws have not yet been developed in the U.S. that protect personal data. In fact, in order for a U.S. company to share and disseminate information with an EU company, the U.S. company must demonstrate compliance with the EU-U.S. Privacy Shield self-certifying process (Willey, White \& Ford, 2016). This emphasizes the stricter data privacy standards the EU requires, in comparison to the U.S. EU court rulings interpreting the Privacy Shield place an onus on corporate IT departments to maintain an awareness of the continuing evolution of data privacy, laws, and obligations (Willey, et al, 2016).

\section{Map-Based Activities and Learning}

Student learning can be categorized as passive or active, and student learning is enhanced when the instruction shifts from passive to active (Steveler, 2017). Passive learning includes activities such as listening to a lecture, viewing a presentation or watching a video (Steveler, 2017). Active learning, however, requires that students interact with new knowledge to enable them to make connections with what they already know and what is new knowledge. The concept of building knowledge stems from the epistemology of constructivism under which a learner creates new knowledge by building on what is already known or what has already been experienced (von Glaserfeld, 1989).

In a class, this may mean that the students are called upon to act in relation to the new content by solving problems or interpreting data (Steveler, 2017). The process of increasing student learning demands increasing the level of student engagement with new material by developing activities that involve observation, action, and reflection (Ni Raghallaigh (2013). Opportunities to apply and analyze knowledge create an environment conducive to active learning (Manzon, 2017), and the more practice a student has in applying new knowledge, the more expertise the student can gain (Bertheussen, B. A. \& Myrland, O., 2016).

Developing maps can be an active learning exercise (Steveler, 2017). Although maps are an integral part of geography education, their significance applies to a wide range of disciplines (Liben, Kastens, \& Stevenson, 2002). In addition to identifying places, maps can be used to explore the relationship between two places and test a student's understanding of representational correspondences between a map and text. Rittschof and Kulhavy (1998) suggest thematic maps can be used to present patterns of data that help students draw inferences about a specific theme. Google Trends has been suggested as one way to add map-based materials to Computer Information Systems courses (White et al., 2014) although it has never been formally tested.

\section{METHODOLOGY}

Both passive map materials and in-class map activities were used in introductory computer information systems courses, and a survey was developed to measure students' globalization awareness (See Appendix A). Of the nineteen survey items dealing with the political dimension of globalization (Steger, 2009), six were drawn from Zollinger, Runfeng, and Campbell (2015). Thirteen additional items dealing with data privacy were developed by business law faculty at a regional comprehensive university in the southeast. An additional five items (Zollinger et al., 2015) were used to measure student awareness of the meaning of globalization.

Prior to the survey administration, five sections of an introductory information systems course were randomly assigned to one of the following two treatment groups: passive thematic map materials or passive thematic maps plus in-class thematic map activities. 


\section{Passive Thematic Map Materials}

Course sections with passive thematic map materials included Google Trends maps relating to course textbook material (See Appendix B). These heat maps appeared as the first item in nine weekly folders representing the nine chapters covered in the course. The maps did not appear in the other six weekly folders that typically contained Access and Excel Lab activities or activities related to an IT in My Career project. The heat maps appeared with a sentence above describing the course-related search term or phrase while the map illustrated the extent to which the term appeared in search phrases in countries around the world. Darker colors on the maps indicated a greater number of searches compared to lighter colors, which indicated a lesser number of searches.

\section{Passive Thematic Maps Plus In-Class Thematic Map Activities}

The instructor demonstrated the use of Google Fusion Tables to create dynamic maps related to three chapter topics roughly every four weeks during the semester (See Appendix B). Fusion Tables allow for data manipulation and visualization, enabling users to upload data files in a variety of formats, including KML (Keyhole Markup Language) and CSV (Comma Separated Values) to easily depict data in different ways.

Students were tasked with using Google Trends to find topics and queries that related to Data Loss Prevention Software, Secure Sockets Layer Certificates, and Data Governance. Students were given ten minutes to download and identify the regions in which the term was most popular over a period dating back to 2004. After the regions were identified by the students, the remaining class time was spent with the instructor demonstrating how to render geographic datasets and visually display tabular data files downloaded from Google Trends. Although the process of rendering polygon shapes that represent world borders was done prior to class due to long processing time, the KML syntax stored in Fusion Tables was reviewed. The data files retrieved from Google Trends were merged using the key column, Country Names, to essentially join the Google Trends data with the geographic datasets. Ultimately resulting in thematic maps, each of the Google Fusion Tables that were created displayed intensity characteristics of the data collected from Google Trends. Web integration and adding additional filters using Google Fusion Tables was also demonstrated to students in subsequent activities.

Over the course of the semester, students in all five course sections were presented with passive map materials, chiefly in the form of images and text, while two of the five sections also were exposed to in-class map activities involving Google Fusion Tables (see Appendix B). Near the end of the semester, students in introductory information systems courses were given the global awareness survey.

\section{RESULTS}

Of the 165 surveys, five surveys were missing responses for the majority of survey items and were removed, leaving 160 that were analyzed. The survey sample contained more males (54.4\%) than females (45.6\%). Demographics for student survey responses appear in Table 1 below:

Table 1. Demographics

\begin{tabular}{|c|l|c|}
\hline Gender & \multicolumn{1}{|c|}{ Activity Type } & \# of Survey Responses \\
\hline \multirow{2}{*}{ Female } & Passive Map Images & 39 \\
\cline { 2 - 3 } & Passive Map Images \& Google Fusion Table Activities with Maps & 34 \\
\hline \multirow{2}{*}{ Male } & Passive Map Images & 43 \\
\cline { 2 - 3 } & Passive Map Images \& Google Fusion Table Activities with Maps & 44 \\
\hline
\end{tabular}

All tests were conducted with a significance level, or alpha, of .05 that the $p$ values were measured against.

\section{Student Globalization Awareness By Activity Type}

An independent samples t-test was performed to determine if student globalization awareness scores differed based on whether map activities were passive or active in nature, and results showed that student globalization awareness did not differ based on activity type. Specifically, with respect to student awareness of globalization meaning, results showed that students who were exposed to passive map activities $(M=3.90, S D=0.53)$ or more active map activities $(M=4.00, S D=0.55)$ did not differ statistically, $t(158)=-1.171, p=.244$. Similarly, with respect to student awareness of political and data privacy laws, students who were exposed to passive map activities $(M=$ 
$3.42, S D=0.33)$ or more active map activities $(M=3.45, S D=0.39)$ also did not differ statistically, $t(158)=-.504$, $p=.615$.

Because globalization awareness scores for passive versus active map activities did not significantly differ, a onesample t-test was performed to determine whether students' awareness of the meaning of globalization and awareness of the political dimension, including data privacy law, differed from the neutral mid-point measure 3. Means were significantly higher than the neutral mid-point measure for both the meaning of globalization $(M=$ $3.95, S D=0.54) t(159)=22.191, p<.000$ and for the political dimension including data privacy laws $(M=3.43, S D$ $=0.36) t(159)=15.124, p<.000)$.

\section{Student Globalization Awareness By Gender and Age}

A post hoc analysis showed that globalization awareness scores for students did not differ based on gender or age. An independent samples t-test was used to determine whether student responses differed based on student gender. Results showed that awareness of the meaning of globalization for male students $(M=3.89, S D=0.57)$ and for female students $(M=4.02, S D=0.50)$ did not differ significantly based on their gender $t(158)=-1.455, p=.148$. Similarly, results showed that student understanding of political and data privacy laws for males $(M=3.43, S D=$ $0.39)$ and for females $(M=3.44, S D=0.33)$ also did not differ based on their gender $t(158)=-.114, p=.909$.

An independent samples t-test was performed to determine whether student responses differed based on the age of the student. The two age groups 18-34, and 35 and older were used to differentiate between younger and older students, respectively. Results showed that the student awareness of the meaning of globalization responses for the items measured did not significantly differ based on whether they were in the younger $(M=3.95, S D=0.56)$ or older $(M=3.93, S D=0.38)$ age groups $t(158)=0.185, p=.854$. Similarly, results showed that student understanding of the political dimension, including data privacy laws, for younger $(M=3.44, S D=0.36)$ and older $(M=3.32, S D=0.33)$ students also did not differ significantly based on their age $t(158)=1.281, p=.202$.

\section{DISCUSSION AND CONCLUSION}

Although there are no statistically significant differences in globalization awareness for students exposed to passive map exercises involving thematic map materials and students exposed to active exercises using Google Fusion Tables and maps, one reason could be related to the survey itself. There are limited survey items in the literature that measure globalization awareness and its various components such as the political dimension including data privacy laws. Development of survey items measuring globalization awareness in the context of information systems courses is an area of future research that would provide great benefit.

Another reason why globalization scores for students didn't differ based on activity type might be due to the nature of the activity itself. Although the active exercise involved Google Fusion Table activities with maps, the exercise mostly involved instructor demonstration while students explored Google Trends on their own. It may be possible to increase the level of student engagement for the in-class activities by grading those activities or by creating an additional homework assignment which may positively impact student globalization awareness. However, exposure to world maps, such as passive map materials, relating to information systems course content, appears to be beneficial to students, which is good news for instructors who may not have several class periods available to devote to additional map-based activities.

\section{REFERENCES}

AACSB International (2011). Globalization of management education: Changing international structures, adaptive strategies, and the impact on institutions, Emerald Group Publishing Limited.

Baylis, J. \& Smith, S. (2001). The Globalization of World Politics: An introduction to international relations (2nd ed.). Oxford, NY: Oxford University Press.

Bertheussen, B.A. \& Myrland, O. (2016). Relation between academic performance and students' engagement in 
digital learning activities. Journal of Education for Business, 91(3), 125-131.

Bruner, R. F., \& Iannarelli, J. (2011). Globalization of management education. Journal of Teaching in International Business, 22(4), 232-242.

Davis, G. B., Gorgone, J. T., Couger, J. D., Feinstein, D. L., \& Longenecker, Jr, H. E. (1997, December). IS'97: model curriculum and guidelines for undergraduate degree programs in information systems. In ACM SIGMIS Database 28(1), 1-94.

Gorgone, J., Davis, G. B., Valacich, J. S., Topi, H., Feinstein, D. L., \& Longenecker, H. E. (2003). IS 2002 model curriculum and guidelines for undergraduate degree programs in information systems. Communications of the Association for Information Systems, 11(1), 1.

Lee, D. (2017, November 22). Uber concealed huge data breach. Retrieved from http://www.bbc.com/news/technology-42075306.

Liben, L. S., Kastens, K. A., \& Stevenson, L. M. (2002). Real-world knowledge through real-world maps: A developmental guide for navigating the educational terrain. Developmental Review, 22(2), 267-322.

Lien, T. (2017, December 22). Alteryx data breach exposed 123 million American households' information. Retrieved from http://beta.latimes.com/business/technology/la-fi-tn-alteryx-data-breach-20171222story.html.

Manzon, E. (2017). Creating student engagement: the Kickstarter active learning project. Marketing Education Review, 27 (2), 115-118.

McPherson, S., Wang, S. K., Hsu, H. Y., Tsuei, M., \& Wood, R. (2007, October). Using Information and Communication Technologies (ICTs) in Teacher Education for Increasing Global Awareness. In E-Learn: World Conference on E-Learning in Corporate, Government, Healthcare, and Higher Education (pp. 1112-1116). Association for the Advancement of Computing in Education (AACE).

Meredith, S., Facebook-Cambridge Analytica: A timeline of the data hijacking scandal. https://www.cnbc.com/2018/04/10/facebook-cambridge-analytica-a-timeline-of-the-data-hijackingscandal.html. Retrieved May 5, 2018.

Ni Raghallaigh, M. \& Cunniffe, R. (2013). Creating a safe climate for active learning and student engagement: an example from an introductory social work module. Teaching in Higher Education, 18 (1), 93-105.

Pew Research Center for the People \& the Press (2003). Views of a changing world: How global publics view: War in Iraq, democracy, Islam and governance, globalization. http://peoplepress.org/reports/display.php3?ReportID=185. Retrieved December 22, 2017.

Rittschof, K. A., \& Kulhavy, R. W. (1998). Learning and remembering from thematic maps of familiar regions. Educational Technology Research and Development, 46(1), 19-38.

Romero, E. J. (2008). AACSB accreditation: Addressing faculty concerns. Academy of Management Learning \& Education, 7(2), 245-255.

Sabin, M., Alrumaih, H., Impagliazzo, J., Lunt, B., Zhang, M., Byers, B., Newhouse, W., Paterson, B., Peltsverger S., Tang, C., Veer. G., \& Viola, B. (2017). Information Technology Curricula 2017: Curriculum Guidelines for Undergraduate Degree Programs in Information Technology. Association for Computing Machinery \& IEEE Computer Society.

Steger, M. B. (2009). Globalization: A Very Short Introduction. Oxford: Oxford University Press. 


\section{Issues in Information Systems}

Volume 19, Issue 2, pp. 47-55, 2018

Steveler, R.A. \& Menekse, M. (2017). Taking a Closer Look at Active Learning. Journal of Engineering Education, 106 (2), 186-190.

Topi, H., Valacich, J. S., Wright, R. T., Kaiser, K., Nunamaker, Jr., J. F., Sipior, J. C., \& de Vreede, G. J. (2010). IS 2010: Curriculum guidelines for Undergraduate Degree Programs in Information Systems.

Communications of the Association for Information Systems, 26, 359-428.

von Glaserfeld, E. (1989). Cognition, Construction of Knowledge, and Teaching, Synthese 80, 121-127.

White, B. J., Hale, M. C., \& Willey, L. (2014). Globalizing security classes using Google Trends. Issues in Information Systems, 15(2), 39-48

Willey, L., White, B. J., \& Ford, J. C. (2014). U.S. EU Safe Harbor \& Privacy Shield: Student exploration of global IT issues and the professions who deal with them. Issues in Information Systems, 17(1), 196-205

Zollinger, B., Runfeng, F., \& Campbell, K. (2015). Undergraduates' Awareness and Perceptions of Globalization: A Comparison of US and Chinese Students. eJournal of Public Affairs, 4(1), 141-157. 


\section{APPENDIX A SURVEY ITEMS}

Political Dimension \& Data Privacy Law Items (5-point Likert Scale: 1=Strongly Disagree; 5=Strongly Agree)

1. In my lifetime, being a world citizen will become more important than being a citizen of a country.

2. Citizens in developing countries have a right to expect improved quality of life for the majority of citizens the more their government allows foreign companies to do business in the country.

3. In producing goods and services businesses have come to rely so much on the ability to obtain resources from around the world that governments are unable to implement policy that will hamper international business dealings.

4. In producing goods and services businesses have come to rely so much on the ability to obtain resources from around the world that governments should not implement policy that will hamper international dealings.

5. It is good to have worldwide nonprofit organizations aimed at meeting needs of citizens regardless of country borders.

6. International cooperation through organizations like the United Nations is something that I hope increases during my lifetime.

7. There should be a single international body, similar to the United Nations, that determines and administers data privacy policy.

8. Multinational businesses in the EU have come to rely so much on the exchange of data that member countries in the EU are unable to implement privacy laws that will restrict the flow of data.

9. In the EU, the economic situation is such that in the past decade, no EU member country has received financial bailout.

10. US data privacy laws apply to US companies doing business in other countries.

11. Multinational businesses in the EU have come to rely so much on the rapid exchange of data that member countries in the EU should not implement privacy laws that will restrict the flow of data.

12. Multinational companies exchanging personally identifying data must only comply with the data privacy laws that apply to the country in which the company originated.

13. Citizens throughout the member countries of the EU have a right to expect a consistent level of protection of personally identifying information.

14. The US has stronger data privacy laws than other countries in the EU.

15. US data privacy laws apply to foreign companies doing business in the US.

16. It would be good to have international data privacy standards so that personally identifying information could be handled consistently without regards to country borders.

17. Citizens throughout the U.S. have a right to expect a consistent level of protection of personally identifying information.

18. Several EU member countries are currently in trade negotiations to withdraw from the EU

19. Over the course of my professional career, I expect multinational data privacy laws to replace the data privacy laws of individual countries.

Meaning of Globalization Items (5-point Likert Scale: 1=Strongly Disagree; 5=Strongly Agree)

1. I believe globalization includes increased human-caused change to the environment that is cross-border or not specific to just one country.

2. I believe globalization includes growing networks of people who join organizations for a common purpose (for example Amnesty International, Greenpeace, etc.).

3. I believe globalization includes increased communication between people and groups across national borders.

4. I believe globalization includes increased cultural transmissions between countries.

5. I believe globalization includes increased trade between countries. 


\section{APPENDIX B \\ PASSIVE MAP MATERIALS AND ACTIVE MAP-BASED EXERCISE MATERIALS \\ Passive Thematic Map-Based Materials}

Chapter 1 includes similar terms to "Business Intelligence" which you can see trending around the world

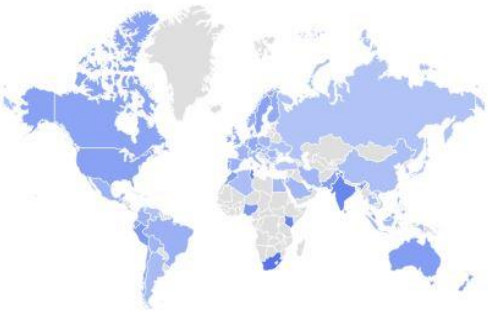

Chapter 4 includes similar terms to "Data Loss Prevention Software" which you can see trending around the world

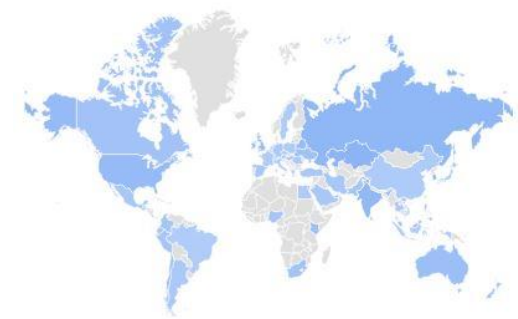

Chapter 7 includes similar terms to "SSL certificate" which you can see trending around the world

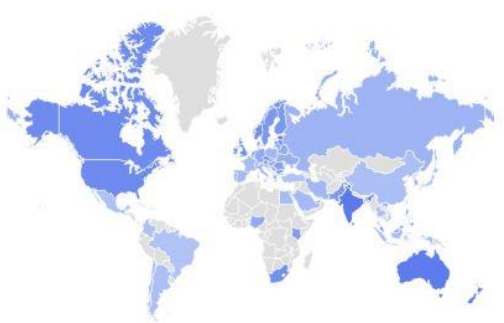

Chapter 2 includes similar terms to "Artificial Intelligence" which you can see trending around the world
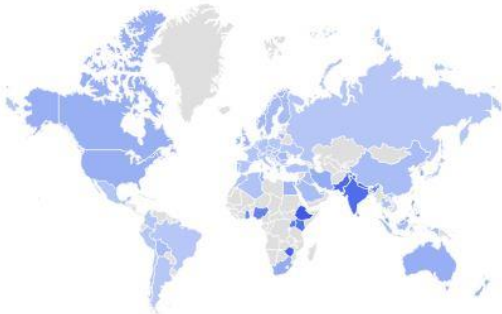

Chapter 5 includes similar terms to "Cloud security" which you can see trending around the world
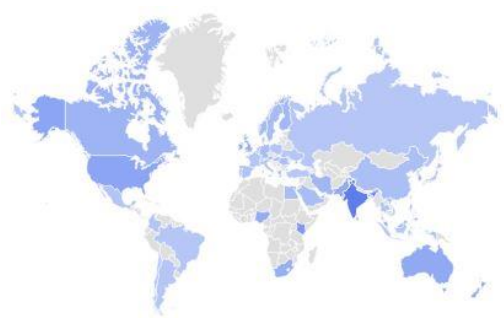

Chapter 8 includes similar terms to "Electronic Data Interchange" which you can see trending around the world

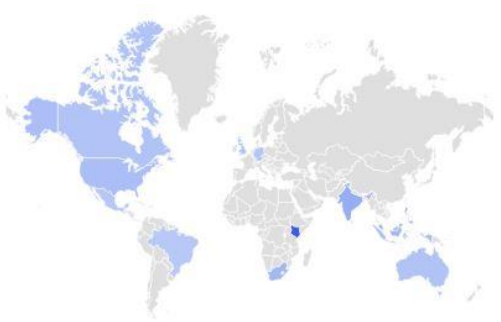

Chapter 3 includes similar terms to "Ecommerce" which you can see trending around the world

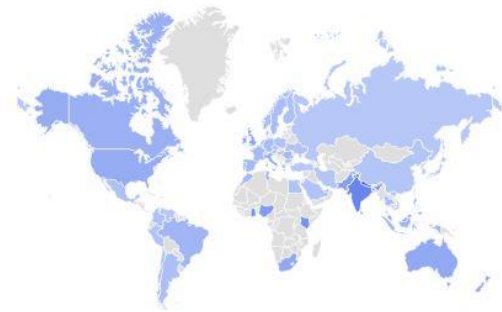

Chapter 6 includes similar terms to "Data governance" which you can see trending around the world

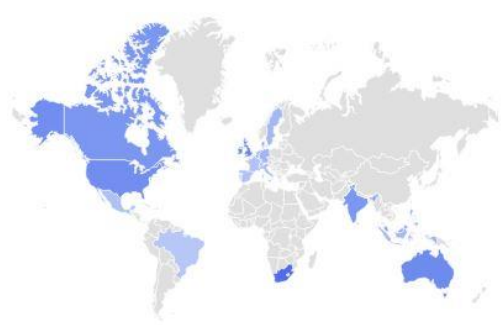

Chapter 9 includes similar terms to "Outsourcing" which you can see trending around the world

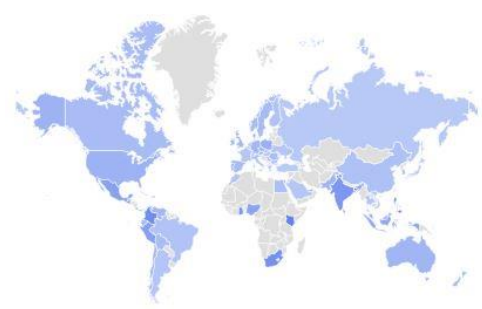

Google Fusion Table Map related to Data Governance

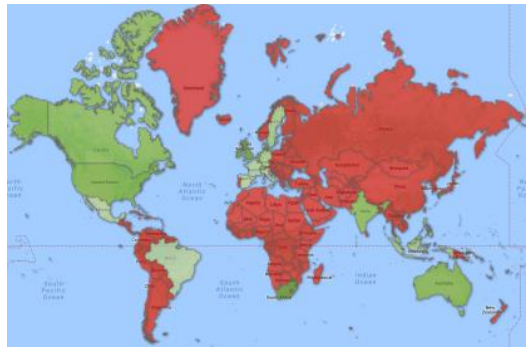

